\title{
Visualization of $\mathrm{Ca}^{2+}$ Filling Mechanisms upon Synaptic Inputs in the Endoplasmic Reticulum of Cerebellar Purkinje Cells
}

\author{
Yohei Okubo, ${ }^{1}$ Junji Suzuki, ${ }_{1}^{1}$ Kazunori Kanemaru, ${ }^{1}$ Naotoshi Nakamura, ${ }^{2}$ Tatsuo Shibata, ${ }^{2}$ and Masamitsu Iino ${ }^{1}$ \\ ${ }^{1}$ Department of Pharmacology, Graduate School of Medicine, The University of Tokyo, Tokyo 133-0033, Japan, and ${ }^{2}$ Laboratory for Physical Biology, \\ RIKEN Quantitative Biology Center, Kobe 650-0047, Japan
}

The endoplasmic reticulum (ER) plays crucial roles in intracellular $\mathrm{Ca}^{2+}$ signaling, serving as both a source and sink of $\mathrm{Ca}^{2+}$, and regulating a variety of physiological and pathophysiological events in neurons in the brain. However, spatiotemporal $\mathrm{Ca}^{2+}$ dynamics within the ER in central neurons remain to be characterized. In this study, we visualized synaptic activity-dependent $\mathrm{ER} \mathrm{Ca}^{2+}$ dynamics in mouse cerebellar Purkinje cells (PCs) using an ER-targeted genetically encoded $\mathrm{Ca}^{2+}$ indicator, G-CEPIAler. We used brief parallel fiber stimulation to induce a local decrease in the ER luminal $\mathrm{Ca}^{2+}$ concentration $\left(\left[\mathrm{Ca}^{2+}\right]_{\mathrm{ER}}\right)$ in dendrites and spines. In this experimental system, the recovery of $\left[\mathrm{Ca}^{2+}\right]_{\mathrm{ER}}$ takes several seconds, and recovery half-time depends on the extent of $\mathrm{ER} \mathrm{Ca}^{2+}$ depletion. By combining imaging analysis and numerical simulation, we show that the intraluminal diffusion of $\mathrm{Ca}^{2+}$, rather than $\mathrm{Ca}^{2+}$ reuptake, is the dominant mechanism for the replenishment of the local $\left[\mathrm{Ca}^{2+}\right]_{\mathrm{ER}}$ depletion immediately following the stimulation. In spines, the ER filled almost simultaneously with parent dendrites, suggesting that the ER within the spine neck does not represent a significant barrier to $\mathrm{Ca}^{2+}$ diffusion. Furthermore, we found that repetitive climbing fiber stimulation, which induces cytosolic $\mathrm{Ca}^{2+}$ spikes in PCs, cumulatively increased $\left[\mathrm{Ca}^{2+}\right]_{\mathrm{ER}}$. These results indicate that the neuronal ER functions both as an intracellular tunnel to redistribute stored $\mathrm{Ca}^{2+}$ within the neurons, and as a leaky integrator of $\mathrm{Ca}^{2+}$ spike-inducing synaptic inputs.

Key words: calcium; endoplasmic reticulum; inositol 1,4,5-trisphosphate; metabotropic glutamate receptor; Purkinje cell

Significance Statement

$\mathrm{Ca}^{2+}$ is a key messenger that regulates neuronal functions in the brain. Although the endoplasmic reticulum (ER) plays indispensable roles as a source and sink of $\mathrm{Ca}^{2+}$, technical difficulties have impeded the analysis of $\mathrm{Ca}^{2+}$ dynamics within the ER. In this study, we have used a genetically encoded $\mathrm{ER} \mathrm{Ca}^{2+}$ indicator to visualize $\mathrm{Ca}^{2+}$ dynamics within the neuronal ER. We found that $\mathrm{Ca}^{2+}$-mobilizing synaptic inputs locally decreased the $\mathrm{ER} \mathrm{Ca}^{2+}$ concentration, followed by $\mathrm{Ca}^{2+}$ replenishment by intraluminal $\mathrm{Ca}^{2+}$ diffusion throughout the ER of dendrites and spines. Furthermore, $\mathrm{Ca}^{2+}$ spike-inducing synaptic inputs cumulatively increased the $\mathrm{Ca}^{2+}$ content of the ER. Thus, our study indicates that the ER functions both as a tunnel to redistribute stored $\mathrm{Ca}^{2+}$ and as a leaky integrator of synaptic inputs.

\section{Introduction}

Understanding the dynamics and regulatory mechanisms of the endoplasmic reticulum (ER) luminal free $\mathrm{Ca}^{2+}$ concentration

\footnotetext{
Received Sept. 17, 2015; revised 0ct. 15, 2015; accepted 0ct. 25, 2015.

Author contributions: Y.O. and M.I. designed research; Y.O., J.S., K.K., and N.N. performed research; J.S. and K.K. contributed unpublished reagents/analytic tools; Y.O., N.N., and T.S. analyzed data; Y.0. and M.I. wrote the paper.

This work was supported by grants from the Ministry of Education, Culture, Sports, Science and Technology, Japan; Takeda Science Foundation; and The Tokyo Society of Medical Sciences. We thank Y. Kawashima for technical assistance.

The authors declare no competing financial interests.

Correspondence should be addressed to Masamitsu lino, Department of Pharmacology, Graduate School of Medicine, The University of Tokyo, 7-3-1 Hongo, Bunkyo-ku, Tokyo 113-0033, Japan. E-mail: iino@m.u-tokyo.ac.jp.
}

$\left(\left[\mathrm{Ca}^{2+}\right]_{\mathrm{ER}}\right)$ is critical for understanding the function of the ER in neurons. In various types of cells, the ER is a major intracellular $\mathrm{Ca}^{2+}$ store and plays a crucial role in intracellular $\mathrm{Ca}^{2+}$ signaling, serving as both a source and a sink of $\mathrm{Ca}^{2+}$. In central neurons, synaptic inputs may evoke $\mathrm{Ca}^{2+}$ release from the ER through two types of $\mathrm{Ca}^{2+}$ release channels, inositol trisphosphate $\left(\mathrm{IP}_{3}\right)$ receptors and ryanodine receptors, thereby regulating a variety of physiological and pathophysiological events (Berridge, 1998; Verkhratsky, 2005). As the driving force for $\mathrm{Ca}^{2+}$ mobilization, $\left[\mathrm{Ca}^{2+}\right]_{\mathrm{ER}}$ is a critical factor for ER-mediated $\mathrm{Ca}^{2+}$ signaling. Al- 
though cell-wide depletion and replenishment of $\mathrm{Ca}^{2+}$ in the neuronal ER have been visualized previously (Fujiwara et al., 2001; Solovyova et al., 2002; Rodriguez-Garcia et al., 2014), the relationship between synaptic inputs and $\mathrm{Ca}^{2+}$ dynamics within the ER remains poorly understood. Previous studies (Brorson et al., 1991; Garaschuk et al., 1997; Finch and Augustine, 1998; Fiorillo and Williams, 1998; Stutzmann et al., 2003; Power and Sah, 2005; Hong and Ross, 2007; Hartmann et al., 2014) have shown that, in neurons, voltage-gated $\mathrm{Ca}^{2+}$ channels induce an influx of $\mathrm{Ca}^{2+}$ that subsequently enhances $\mathrm{Ca}^{2+}$ release. Although this priming effect is thought to increase the $\mathrm{ER} \mathrm{Ca}^{2+}$ content by activating the sarcoplasmic/endoplasmic reticulum $\mathrm{Ca}^{2+}$ ATPase (SERCA), the actual $\mathrm{Ca}^{2+}$ concentration of the ER has not been directly examined, due in part to the lack of appropriate technologies for monitoring $\mathrm{ER} \mathrm{Ca}^{2+}$ dynamics. This limitation represents a major obstacle in studying the function of the neuronal ER.

In earlier studies (Garaschuk et al., 1997), $\mathrm{Ca}^{2+}$ concentration within the ER could be estimated only by indirect measurement of changes in cytoplasmic $\mathrm{Ca}^{2+}$ concentration in response to activation of $\mathrm{Ca}^{2+}$ release from the ER. However, interpretation of such results has been inevitably complicated by changes in the $\mathrm{Ca}^{2+}$ mobilization mechanisms themselves, and has therefore prompted the development of technologies to directly measure $\mathrm{Ca}^{2+}$ dynamics in the ER. One such method is the use of small molecular $\mathrm{Ca}^{2+}$ indicators; however, difficulty in targeting them to the lumen of the ER has limited their application in intact neurons (Fujiwara et al., 2001; Solovyova et al., 2002). In contrast, genetically encoded $\mathrm{Ca}^{2+}$ indicators (GECIs) can be targeted to the ER by tagging with appropriate ER retention signals. This capability has been exploited to develop a variety of GECIs for the visualization of $\mathrm{ER} \mathrm{Ca}^{2+}$ dynamics (Miyawaki et al., 1997; Palmer et al., 2004; Ishii et al., 2006; Tang et al., 2011; Bonora et al., 2013; Rodriguez-Garcia et al., 2014; Wu et al., 2014). To improve the spatiotemporal resolution of GECIs, we recently developed a series of calcium-measuring organelle-entrapped protein indicators (CEPIAs), which are GECIs that can provide highresolution visualization of $\mathrm{ER} \mathrm{Ca}^{2+}$ dynamics in various types of cells, including neurons (Suzuki et al., 2014).

In this study, we expressed the ER-targeted genetically encoded $\mathrm{Ca}^{2+}$ indicator G-CEPIAler in mouse cerebellar Purkinje cells (PCs), which possess a well developed ER with a high density of $\mathrm{IP}_{3}$ receptors (Martone et al., 1993; Sharp et al., 1993). We then evoked synaptic inputs from parallel fibers (PFs) and climbing fibers (CFs), and observed how the ER network within the PCs responded to those inputs. Collectively, these $\mathrm{ER} \mathrm{Ca}^{2+}$ visualization studies provide important new insights into synaptically evoked $\left[\mathrm{Ca}^{2+}\right]_{\mathrm{ER}}$ dynamics.

\section{Materials and Methods}

Gene construction. For PC-specific expression of G-CEPIA1er, we produced a Sindbis virus (Okubo et al., 2001, 2004; Suzuki et al., 2014). The pSinRep5 subcloning version of G-CEPIAler was used as the template for in vitro transcription using SP6 RNA polymerase (Ambion). The RNA transcript and the helper RNA from DH(26S) cDNA template (Invitrogen) were cotransfected into BHK cells by electroporation. Twentyfour hours after transfection, the culture medium containing the infectious particles was harvested. Sindbis virus encoding G-GECO1.1 (Zhao et al., 2011) for the cytoplasmic $\mathrm{Ca}^{2+}$ measurement was also produced by the same procedure.

Infection of PCs and preparation of cerebellar slices. All animal experiments were performed in accordance with the regulations and guidelines of the Institutional Animal Care and Use Committee at The University of Tokyo and were approved by the institutional review committees of the Graduate
School of Medicine, University of Tokyo. Male C57BL/6 mice (postnatal day 21-27) were deeply anesthetized with pentobarbital, and the surface of cerebellar lobule 6 adjacent to the midline was exposed by removing the cranium and dura. The tip of a glass pipette was backfilled with the viral solution. The glass pipette was then inserted into the cerebellum, and $1 \mu \mathrm{l}$ of viral solution was delivered at a rate of $200 \mathrm{nl} / \mathrm{min}$ using a micropump (Legato 130, KD Scientific). Twenty-three to $26 \mathrm{~h}$ after virus injection, parasagittal cerebellar slices ( $250 \mu \mathrm{m}$ thickness) were prepared as described previously (Edwards et al., 1989). Slices were incubated in a holding chamber containing artificial CSF (ACSF) bubbled with $95 \% \mathrm{O}_{2}$ and $5 \% \mathrm{CO}_{2}$ at $35^{\circ} \mathrm{C}$ for $1 \mathrm{~h}$ and then returned to $23^{\circ} \mathrm{C}$. ACSF for slicing and incubation contained the following (in mM): $125 \mathrm{NaCl}, 2.5 \mathrm{KCl}, 2 \mathrm{CaCl}_{2}, 1 \mathrm{MgSO}_{4}, 1.25 \mathrm{NaH}_{2} \mathrm{PO}_{4}$, $26 \mathrm{NaHCO}_{3}$, and 20 glucose.

Imaging. Imaging was performed with a two-photon microscope (TSC MP5, Leica) that was equipped with a water-immersion objective $(25 \times$, numerical aperture, 0.95; HCS IR APO, Leica) and a Ti:sapphire laser (MaiTai DeepSee, Spectra Physics). Slices were transferred to a recording chamber under microscope, continuously perfused with ACSF bubbled with $95 \% \mathrm{O}_{2}$ and $5 \% \mathrm{CO}_{2}$, and supplemented with $10 \mu \mathrm{M}$ bicuculline (Tocris Bioscience) to block spontaneous IPSCs. The excitation wavelength was 900-920 nm. Emitted fluorescence was filtered using an infrared-ray cutting filter, separated by a $560 \mathrm{~nm}$ dichroic mirror and detected with photomultiplier tubes. A 500-550 nm barrier filter and a $600 \mathrm{~nm}$ long-pass filter were used for the green and red channels, respectively. Data were acquired with time-lapse XY-scan mode $(8-10 \mathrm{~Hz}$ for PF-induced responses and $1-2 \mathrm{~Hz}$ for CF-induced responses). For higher-frequency sampling, line-scan mode $(200-400 \mathrm{~Hz})$ was applied. For the focal stimulation of PFs, five square pulses ( $0.1 \mathrm{~ms}$ duration) were applied at $100 \mathrm{~Hz}$ through stimulation pipettes (3-6 $\mu \mathrm{m}$ tip diameter) filled with ACSF and placed just above the imaging field. The stimulation intensity was adjusted within $2-5 \mathrm{~V}$ to induce G-CEPIAler responses confined within narrow dendritic segments $(\sim 5-10 \mu \mathrm{m}$ in diameter of detectable signals). During PF simulation with $2 \times$ intensity (i.e., $4-10$ $\mathrm{V})$, 2,3-dihydroxy-6-nitro-7-sulfonyl-benzo[f]quinoxaline (NBQX) was included in ACSF to avoid the excessive AMPAR-dependent $\mathrm{Ca}^{2+}$ influx and its possible effect on ER $\mathrm{Ca}^{2+}$ dynamics. For CF stimulation, square pulses $(0.1 \mathrm{~ms}, 0-20 \mathrm{~V})$ were applied at $1 \mathrm{~Hz}$ through stimulation pipettes placed on the granule cell layer adjacent to the soma of the PC of interest. For the local application of 3,5-dihydroxyphenylglycine (DHPG), DHPG was pressure ejected ( $1 \mathrm{~mm}, 50 \mathrm{~ms}, 10-30 \mathrm{psi})$ using a fine pipette $(<1 \mu \mathrm{m}$ tip diameter) placed $5-15 \mu \mathrm{m}$ above the dendrite of G-GECO1.1-expressing PCs. Bicuculline, $(S)-(+)$ - $\alpha$-amino-4-carboxy2-methylbenzeneacetic acid (LY367385), NBQX, cyclopiazonic acid (CPA), and DHPG were obtained from Tocris Bioscience. Drugs other than DHPG were dissolved in ACSF and administered through the perfusion system of the recording chamber. Experiments were performed at room temperature $\left(\mathrm{RT} ; 22-24^{\circ} \mathrm{C}\right)$, unless otherwise stated.

Data analysis. Data were analyzed using ImageJ software. Fluorescence intensities were corrected for background fluorescence by measuring a nonfluorescent area. When necessary, photobleaching was corrected using a linear fit to the fluorescence intensity change in nonstimulated area. The fractional change in fluorescence intensity from the basal level $\left(\Delta F / F_{0}\right)$ was analyzed. The amplitude of PF-induced G-CEPIA1er responses was defined as the maximum decrease in $\Delta F / F_{0}$ after PF stimulation. The amplitude of CF-induced G-CEPIAler responses was defined as the maximum increase in $\Delta F / F_{0}$ during 20 pulses of CF stimulation. The amplitude of DHPG-induced G-GECO1.1 responses was defined as the maximum increase in $\Delta F / F_{0}$. For the measurement of amplitude, time courses of $\Delta F / F_{0}$ were smoothed by a moving average with a fiveframe window. The amplitude shown in Figure $2 E$ is defined as the average of $\Delta F / F_{0}$ within the $1 \mathrm{~s}$ (for X-rhod-1) or $5 \mathrm{~s}$ (for G-CEPIAler) time windows, starting from the end of PF stimulation. For the measurement of half recovery time $\left(t_{1 / 2}\right)$, the decay phase of PF-induced G-CEPIAler response was fitted with the exponential function, including a linear component. The time point (with $t=0$ set at the end of PF stimulation) at which $\Delta F / F_{0}$ recovered by half was calculated using the fitted function and measured amplitude. Time to peak was defined as the time between the end of PF stimulation and the point of maximum decrease in $\Delta F / F_{0}$, the location of which was determined after data smoothing using 5 data 
A
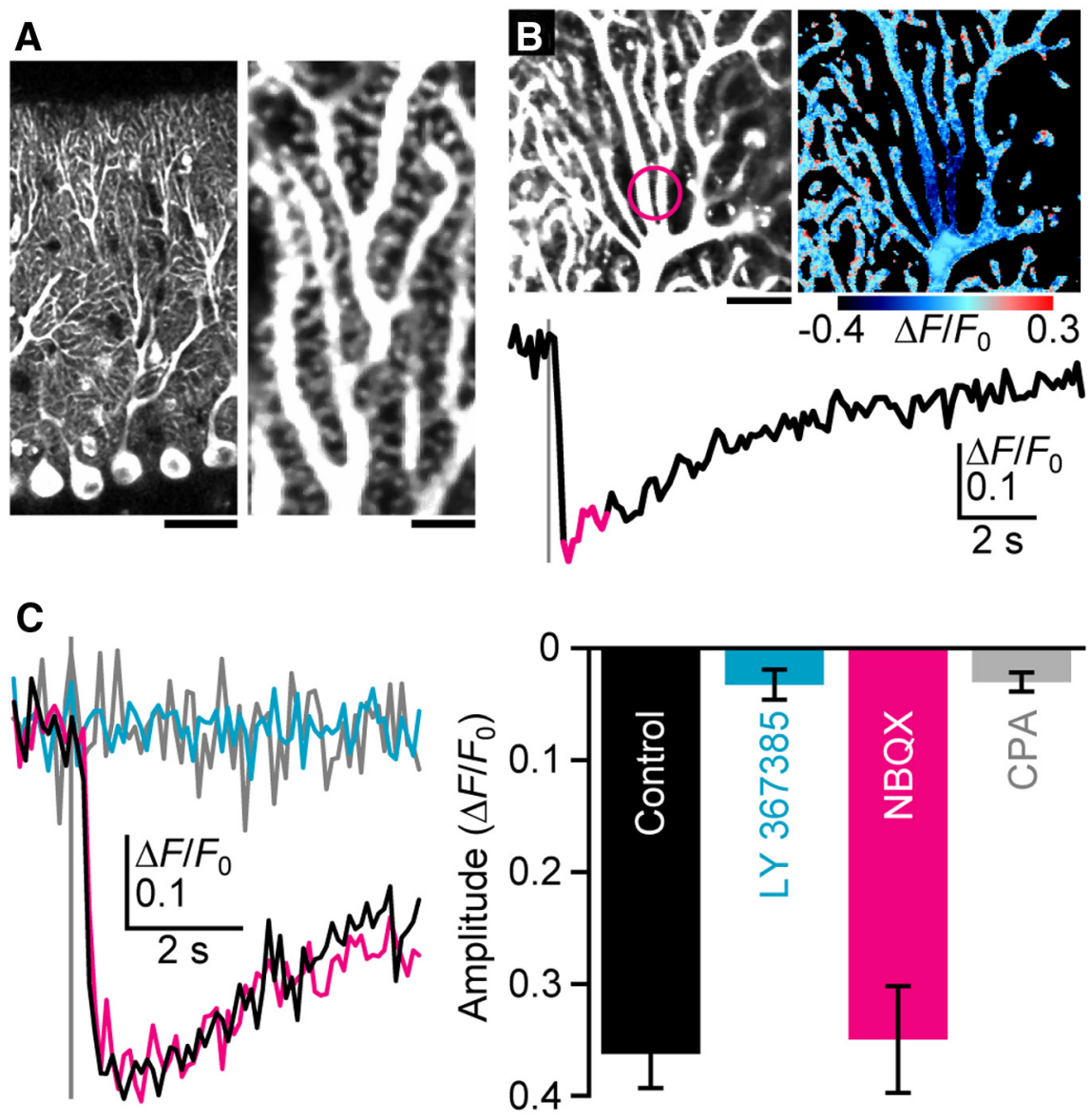

D

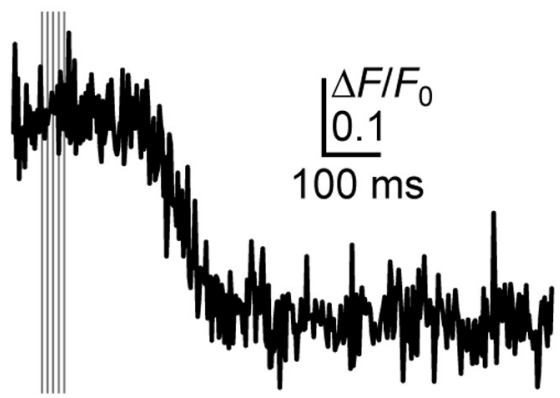

E

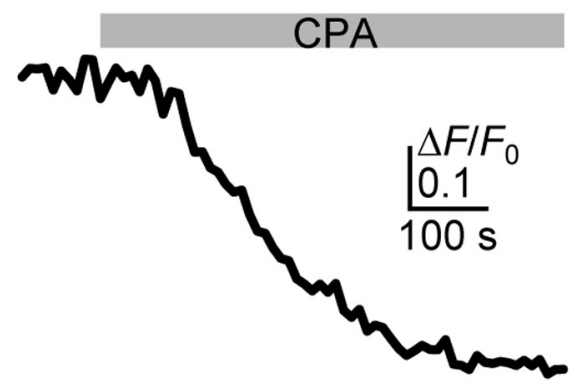

Figure 1. Visualization of PF-induced ER $\mathrm{Ca}^{2+}$ dynamics. $A, \mathrm{G}$-CEPIA1er-expressing PCs in the cerebellar slice. Scale bars: left, $40 \mu \mathrm{m}$; right, $4 \mu \mathrm{m}$. $B$, Representative time course of mean $\Delta F / F_{0}$ values within the dendritic segment (indicated by the circle in the top left image) upon PF inputs (five stimuli at $100 \mathrm{~Hz}$, gray vertical line) indicates PF-induced ER $\mathrm{Ca}^{2+}$ dynamics in PCs. The pseudo-color image represents the average of 10 consecutive frames (indicated as magenta in the time course of $\Delta F / F_{0}$ ). Scale bar, $10 \mu \mathrm{m}$. C, Pharmacological characterization of PF-induced ER Ca ${ }^{2+}$ dynamics. G-CEPIA1er responses upon PF inputs (five stimuli at $100 \mathrm{~Hz}$, gray vertical line) in the control condition (black); in the presence of LY367385 (100 $\mu \mathrm{m}$, cyan) or NBQX (10 $\mu \mathrm{m}$, magenta); or after the depletion of ER with CPA (50 $\mu \mathrm{m}$, gray) are shown. Amplitude is defined as the maximum decrease in $\Delta F / F_{0}$ within the $3 \mathrm{~s}$ time window after PF stimulation. $n=7-12$ (mean \pm SEM). $D$, High-frequency measurement of PF-induced $\mathrm{G}$-CEPIA1er response. Time course of $\Delta F / F_{0}$ upon PF inputs (five stimuli at $100 \mathrm{~Hz}$, gray vertical line) was measured by the line-scan imaging of the dendrite. $E$, CPA-induced ER depletion. The application of CPA (50 $\mu \mathrm{M}$, gray) decreased G-CEPIA1er fluorescence with the $\Delta F / F_{0}$ amplitude of $0.43 \pm 0.021$ (mean $\pm \mathrm{SEM}, n=6$ ).

point moving average. To avoid overestimation of the time to peak, we discarded data if the $\Delta F / F_{0}$ trace had no recognizable trough at distal locations. To analyze the diffusional dynamics in PF-induced G-CEPIAler responses, we manually determined the central point of the response by carefully inspecting the spatial distribution of $\Delta F / F_{0} 1-2 \mathrm{~s}$ after PF stimulation. If responses covered more than one dendritic branch, the central points were set in each dendrite. Distance was mea- sured along the skeletonized dendrites that consist of the manually delineated centerlines of dendrites.

Fluorescence recovery after photobleaching (FRAP) experiments. G-CEPIA1er was bleached by the illumination of an excitation laser $(900-$ $920 \mathrm{~nm}$ ) within a 5 - $\mu \mathrm{m}$-diameter circle. Amplitude was defined as $\Delta F / F_{0}$ just after the end of photobleaching. For the measurement of $t_{1 / 2}$, the recovery phase of G-CEPIAler fluorescence was fitted with the exponential function, including a linear component. The time point (with $t=0$ set at the end of photobleaching) at which $\Delta F / F_{0}$ recovered by half was calculated using the fitted function and measured amplitude.

Patch-clamp experiments. Whole-cell patchclamp experiments were performed for the simultaneous visualization of cytoplasmic $\mathrm{Ca}^{2+}$ concentration $\left(\left[\mathrm{Ca}^{2+}\right]_{\mathrm{cyt}}\right)$ and $\left[\mathrm{Ca}^{2+}\right]_{\mathrm{ER}}$ dynamics, and the recording of CF-induced EPSPs. The resistances of patch pipettes were 4-7 M $\Omega$ when filled with the intracellular solution containing the following (in $\mathrm{mM}$ ): 130 K-gluconate, $4 \mathrm{MgCl}_{2}, 4 \mathrm{Na}_{2} \mathrm{ATP}, 0.4 \mathrm{Na}_{2}$ GTP, 10 sodium phosphocreatine, 3 sodium L-ascorbate, and 10 HEPES, $\mathrm{pH}$ 7.3, adjusted with $\mathrm{KOH}$. The intracellular solution also contained $0.1 \mathrm{~mm} \mathrm{X-rhod-1} \mathrm{(Anaspec)} \mathrm{or} 0.2$ mM EGTA. For the simultaneous visualization of $\left[\mathrm{Ca}^{2+}\right]_{\mathrm{cyt}}$ and $\left[\mathrm{Ca}^{2+}\right]_{\mathrm{ER}}$ dynamics, $\mathrm{X}$-rhod-1 was introduced to the cytoplasm of G-CEPIA1er-expressing PCs via patch pipettes. PCs were held at -60 to $-70 \mathrm{mV}$ with an EPC-9 patch-clamp amplifier (HEKA) using the voltage-clamp mode. NBQX was included in ACSF to isolate ER-mediated $\left[\mathrm{Ca}^{2+}\right]_{\text {cyt }}$ responses by inhibiting AMPARdependent $\mathrm{Ca}^{2+}$ influx. CF-induced EPSPs were recorded with an EPC-9 patch-clamp amplifier using the current-clamp mode. The intensity of CF stimulation pulses was set just above the threshold to induce CF-induced EPSPs, and the intensity just below the threshold was applied for nonspiking controls. The on-line data acquisition and off-line analysis of data were performed using PULSE software (HEKA).

Modeling of $\mathrm{ER} \mathrm{Ca}^{2+}$ dynamics. The time evolution of $\mathrm{ER} \mathrm{Ca}^{2+}$ concentration after PFinduced local depletion was modeled by the following one-dimensional reaction-diffusion equation:

$$
\frac{d u}{d t}=D \nabla^{2} u-k\left(u-u_{0}\right) .
$$

The equation describes lateral diffusion of ER $\mathrm{Ca}^{2+}$ and SERCA-dependent $\mathrm{Ca}^{2+}$ uptake, and $u$ (in $\mu \mathrm{M}$ ), $u_{0}$ (in $\left.\mu \mathrm{M}\right), D$ (in $\mu \mathrm{m}^{2} / \mathrm{s}$ ), and $k$ (in s) denote $\mathrm{ER} \mathrm{Ca}^{2+}$ concentration, basal ER $\mathrm{Ca}^{2+}$ concentration, the diffusion coefficient of $\mathrm{Ca}^{2+}$, and SERCA activity, respectively. The term $k\left(u-u_{0}\right)$ shows the contribution of $\mathrm{ER} \mathrm{Ca}^{2+}$ leak channels and SERCA $\mathrm{Ca}^{2+}$ pumps. Since $\left[\mathrm{Ca}^{2+}\right]_{\text {cyt }}$ is nearly constant during the ER $\mathrm{Ca}^{2+}$ recovery phase (see Fig. $2 D$ ), SERCA activity, which depends on $\left[\mathrm{Ca}^{2+}\right]_{\text {cyt }}$, was set to be constant in the model. Boundary conditions at the end of dendrites were chosen to be either Dirichlet (equal to basal concentration) or Neumann (zero flux) according to the actual dendrite 
A
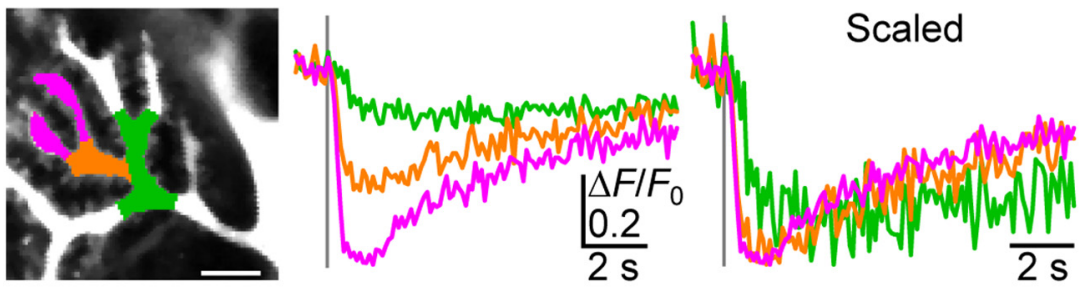

B
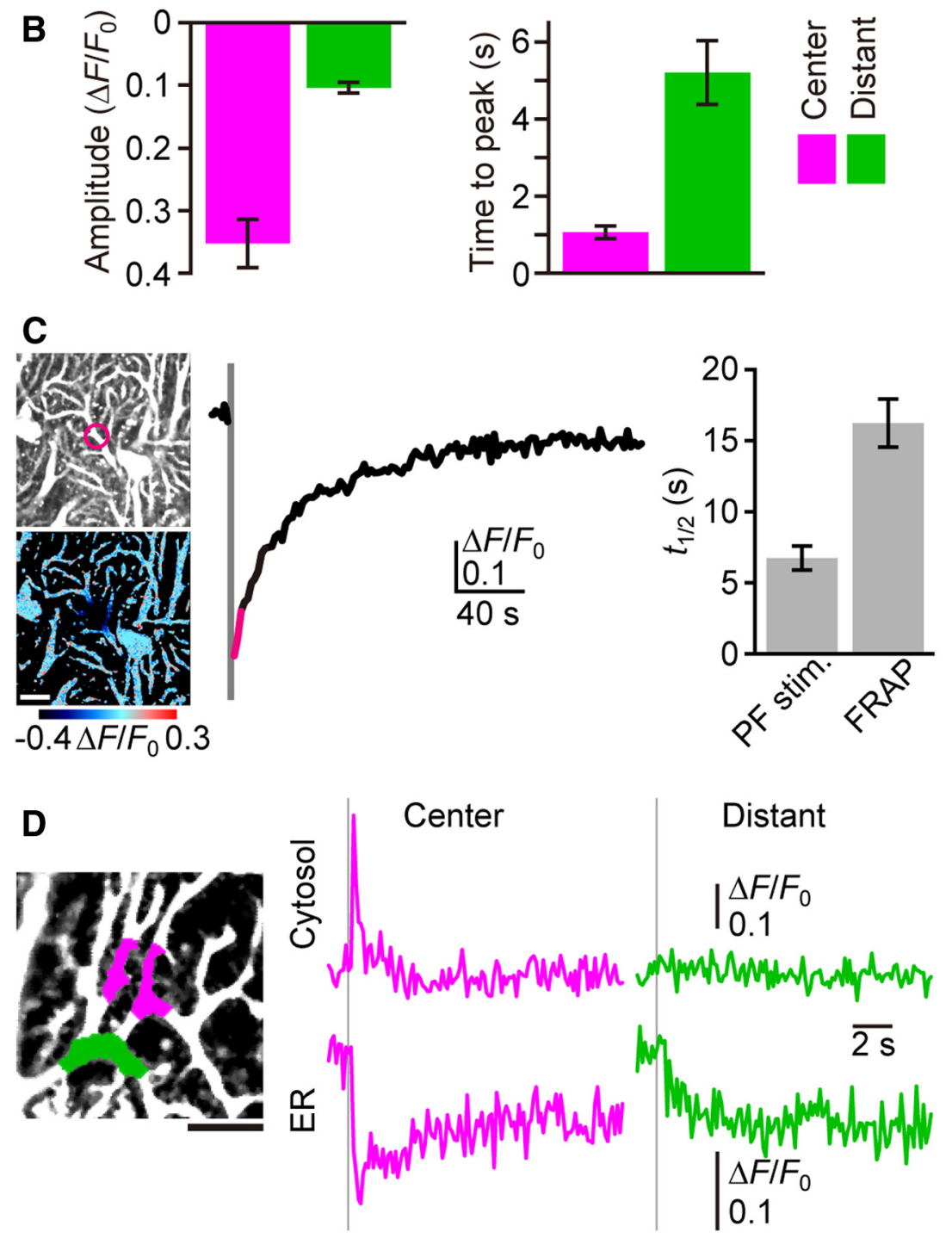

E

Cytosol

ER
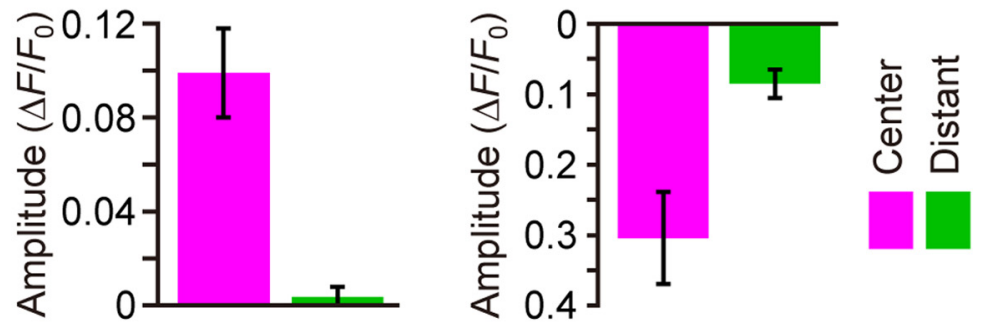

Figure 2. Lateral diffusion of $\mathrm{Ca}^{2+}$ within ER. $A$, Lateral diffusion of luminal $\mathrm{Ca}^{2+}$, as suggested by the wave-like propagation of the G-CEPIA1er response. Dendritic segments and corresponding $\Delta F / F_{0}$ traces upon PF inputs (five stimuli at $100 \mathrm{~Hz}$, gray vertical line) were color coded (magenta, orange, and green). Scale bar, $5 \mu \mathrm{m}$. B, Summary of differences between the central and distant segment of PF-induced responses. Center (magenta) was defined as dendritic segments within $5 \mu \mathrm{m}$ from the central point, and geometry. Diffusion in a tube of abruptly changing diameter can be described by a onedimensional diffusion equation with a constant diffusion coefficient (Berezhkovskii et al., 2009; Makhnovskii et al., 2010). Borrowing from this theory, we reduced the diffusion through the dendritic branching (see Fig. 3A) to one-dimensional diffusion with alternating diameter as follows. We aligned and merged branches along the distance from the central point of response, and let the merged segments possess the pump/leak coefficient $(k)$ multiplied by the number of merged branches. The $\mathrm{Ca}^{2+}$ diffusion coefficient $(D)$ was assumed to be constant throughout the one-dimensional structure. The simulated ER $\mathrm{Ca}^{2+}$ concentration $u$ was converted to G-CEPIAler fluorescence $F$ using the following equation, which was described previously (Suzuki et al., 2014):

$$
F=F_{\min }+\left(F_{\max }-F_{\min }\right) \times u^{n} /\left(u^{n}+K_{\mathrm{d}}^{n}\right),
$$

and was compared with experimental data. The following values from Suzuki et al. (2014) were used: The maximum fractional change in the fluorescence intensity $\left(F_{\max } / F_{\min }\right)=4.7$, $K_{\mathrm{d}}=672 \mu \mathrm{M}, n=1.95$. For Figure $3 A$, the following values were selected to fit the model to the data: $D=8.4070, k=0.0146, u_{0}=995.6$. These values were determined using an automated trial-and-error, parameter-optimizing program written in MATLAB version 8.3. The basal ER $\mathrm{Ca}^{2+}$ concentration $\left(u_{0}=995.6 \mu \mathrm{M}\right)$ that we obtained was comparable to the resting $\left[\mathrm{Ca}^{2+}\right]_{\mathrm{ER}}$ measured in other cell types in our recent study (Suzuki et al., 2014).

\section{Results}

Visualizing synaptically evoked ER $\mathrm{Ca}^{2+}$ dynamics with G-CEPIA1er We used Sindbis virus to express G-CEPIAler in PCs and a two-photon microscope to image its expression in acute cerebellar slices, first focusing on

distant (green) was defined as segments $>7 \mu \mathrm{m}$ distal to the central point (for details, see Materials and Methods). $n=8$ (mean $\pm S E M)$. $C$, Time course of $\Delta F / F_{0}$ within the dendritic segment (indicated by the circle in the left image) indicates the decrease in fluorescence upon photobleaching (gray vertical line) and the subsequent recovery (FRAP). The pseudocolor image that is the average of three consecutive frames (indicated as magenta in the time course of $\Delta F / F_{0}$ ) shows local fluorescence decrease. $t_{1 / 2}$ upon PF inputs is indicated for comparison in the right bar graph. $n=10$ (mean \pm SEM). Scale bar, $10 \mu \mathrm{m}$. D. Cytosolic and ER $\mathrm{Ca}^{2+}$ dynamics visualized by introducing X-rhod-1 to the cytosol of G-CEPIA1er-expressing $P C$ s. Time courses of $\Delta F / F_{0}$ for $X$-rhod-1 (cytosol) and G-CEPIA1er (ER) within the central segment (magenta) or the distant segment (green) upon PF inputs (five stimuli at $100 \mathrm{~Hz}$, gray vertical line) are shown. NBQX (10 $\mu \mathrm{m})$ was applied to isolate mGluR1-dependent responses. Scale bar, $10 \mu \mathrm{m}$. $\boldsymbol{E}$, Summary of differences between the central and distant segments of PF-induced cytosolic and ER $\mathrm{Ca}^{2+}$ responses. Amplitude is defined as the average of $\Delta F / F_{0}$ within the $1 \mathrm{~s}$ (for cytosol) or $5 \mathrm{~s}$ (for ER) time window starting from the end of PF stimulation. $n=5$ (mean \pm SEM) 

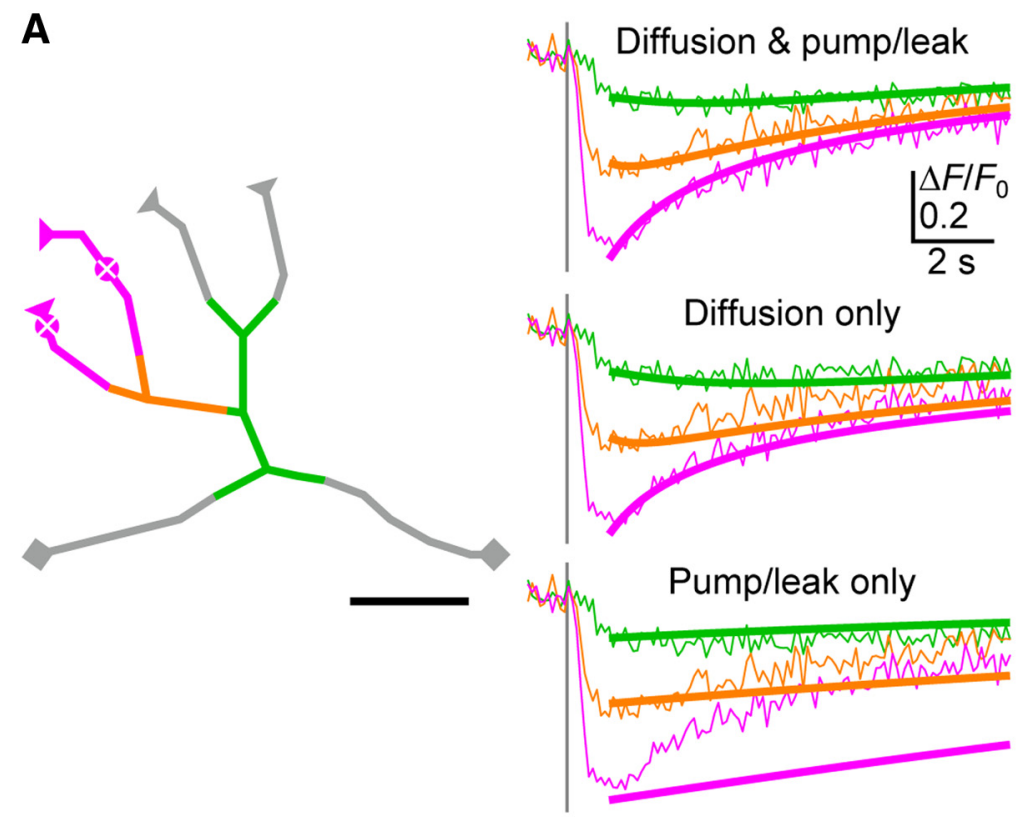

B

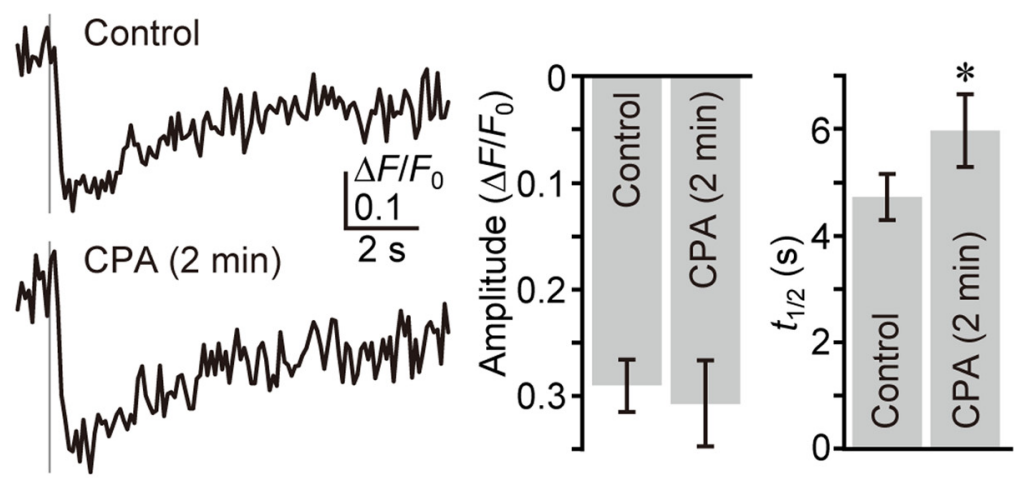

C
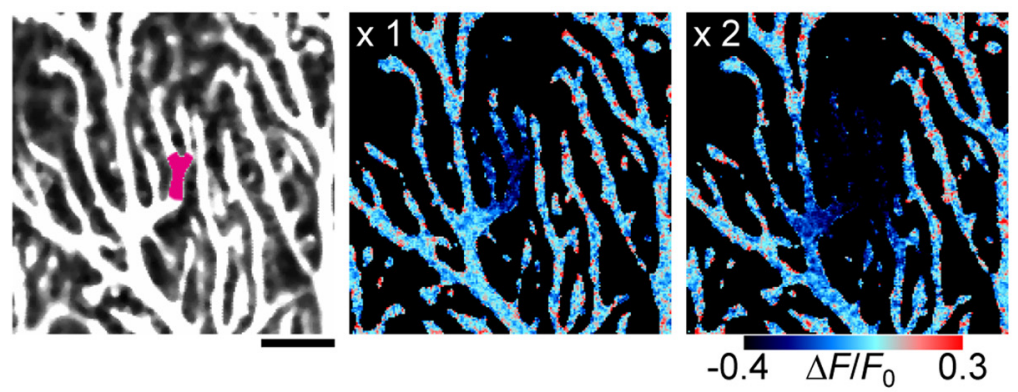

D

E
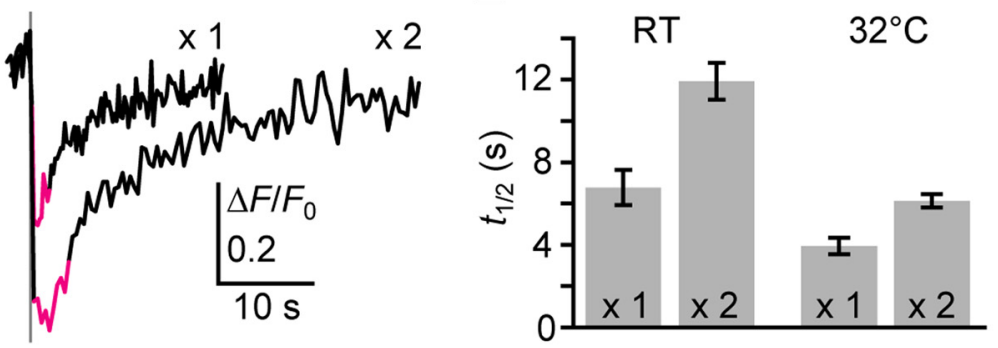

Figure 3. Contribution of intraluminal $\mathrm{Ca}^{2+}$ diffusion to ER refilling after PF inputs. $A$, Numerical simulation of ER $\mathrm{Ca}^{2+}$ dynamics during the refilling period. Left, The actual dendritic structure shown in Figure $2 A$ was manually skeletonized, and reaction-diffusion modeling performed. The triangles on the terminals indicate the dead-end boundary, while the squares indicate the open-end boundary. Dendritic segments for the calculation of $\Delta F / F_{0}$ were indicated by colors, as in Figure $2 A$. The central

dendrites (Fig. 1; see Fig. 4, data for spines). We observed G-CEPIAler expression throughout dendrites and spines (Fig. 1A), which was consistent with earlier reports on the distribution pattern of the ER in PCs (Martone et al., 1993; Sharp et al., 1993). It has been well documented that PF inputs induce metabotropic glutamate receptor 1 (mGluR1)- $\mathrm{IP}_{3}$-mediated local $\mathrm{Ca}^{2+}$ release from the ER, which increases the $\left[\mathrm{Ca}^{2+}\right]_{\mathrm{cyt}}$ in PC dendrites and spines (Finch and Augustine, 1998; Takechi et al., 1998; Okubo et al., 2004). Indeed, in response to focal PF stimulation with a physiologically relevant stimulation pattern (five pulses at $100 \mathrm{~Hz}$ ), we observed a transient decrease in G-CEPIAler fluorescence intensity in dendrites and spines confined within a narrow segment [Fig. $1 B$; preliminary observations were shown in our recent report (Suzuki et al., 2014)].

We next pharmacologically manipulated the intracellular signaling mechanism involved in PF-induced $\mathrm{ER} \mathrm{Ca}^{2+}$ dynamics. First, we showed that, as expected, the application of LY367385 (Fig. $1 C$, cyan), an mGluR1 antagonist, blocked the PF-induced G-CEPIAler response that results from $\mathrm{mGluR} 1-\mathrm{IP}_{3}$ mediated $\mathrm{Ca}^{2+}$ mobilization at PF-PC synapses (Finch and Augustine, 1998; Takechi et al., 1998; Okubo et al., 2004). Furthermore, using highly resolved temporal measurements of the PF-induced G-CEPIAler response, we demonstrated that immediately following PF stimula-

points of response (the bottom points of the initial distribution of $\left.\left[\mathrm{Ca}^{2+}\right]_{\mathrm{ER}}\right)$ were marked. Scale bar, $5 \mu \mathrm{m}$. Right, The recovery phase of G-CEPIA1er response was fitted to the model. $\Delta F / F_{0}$ traces (thin lines) are color coded as for those shown in Figure $2 A$. The reaction-diffusion model faithfully reproduced the recovery time course in each dendritic segment (thick lines). The calculated effective diffusion coefficient of $\mathrm{Ca}^{2+}$ in ER lumen was $8.4 \mu \mathrm{m}^{2} / \mathrm{s}$. Simulated results for no diffusion and no pump/leak were produced by resetting the each coefficient to 0 after data fitting. For details, see Materials and Methods. $\boldsymbol{B}$, The effect of short-term treatment with CPA (50 $\mu \mathrm{m}, 2 \mathrm{~min}$ ) on the replenishment rate. Representative time courses of $\Delta F / F_{0}$ upon $P F$ inputs (five stimuli at $100 \mathrm{~Hz}$, gray vertical line), and the summarized bar graph for $\Delta F / F_{0}$ amplitude and $t_{1 / 2}$ are shown. $t_{1 / 2}$ is the time point at which $\Delta F / F_{0}$ recovered by half. $n=7$ (mean \pm SEM). ${ }^{*} p=0.00581$, $t$ test. $C$, The area of PF-induced $\left[\mathrm{Ca}^{2+}\right]_{E R}$ decrease was enlarged by a twofold increase of stimulation intensity (indicated as $\times 2$ ). The pseudo-color images are the averages of 10 consecutive frames (indicated as magenta in $\Delta F / F_{0}$ traces in $D$ ). Scale bar, $10 \mu \mathrm{m}$. $D$, Representative time courses of $\Delta F / F_{0}$ within the dendritic segment (indicated by magenta in the top left image in C) upon PF inputs (five stimuli at $100 \mathrm{~Hz}$, gray vertical line). $\boldsymbol{E}$, The summarized bar graph for $t_{1 / 2}$ under RT or $32^{\circ} \mathrm{C}$. $(n=8$ each, mean \pm SEM). 
tion, there was a $\sim 200 \mathrm{~ms}$ period of latency, which is consistent with previous observations of mGluR1-IP ${ }_{3}$-mediated cytoplasmic $\mathrm{Ca}^{2+}$ transients (Finch and Augustine, 1998; Takechi et al., 1998; Okubo et al., 2004; Fig. 1D). This result indicates that the $\mathrm{Ca}^{2+}$ dissociation kinetics of G-CEPIAler is fast enough to follow the synaptically evoked $\left[\mathrm{Ca}^{2+}\right]_{\mathrm{ER}}$ dynamics. In contrast, the application of NBQX (Fig. 1C, magenta), an AMPAR antagonist, had no effect on ER $\mathrm{Ca}^{2+}$ dynamics. On the other hand, the application of CPA, a SERCA inhibitor, induced slow depletion of $\mathrm{ER} \mathrm{Ca}^{2+}$ (Fig. 1E), followed by abolishment of the G-CEPIAler response to PF stimulation (Fig. 1C, gray). In conclusion, G-CEPIA1er enabled the visualization of $\mathrm{ER} \mathrm{Ca}^{2+}$ dynamics confined to the vicinity of PF inputs in PCs, which allowed us to analyze the molecular mechanisms for refilling the ER with $\mathrm{Ca}^{2+}$, following synaptically evoked $\mathrm{Ca}^{2+}$ mobilization in neurons.

Lateral diffusion of $\mathrm{Ca}^{2+}$ within the ER After $\mathrm{Ca}^{2+}$ is depleted cell wide throughout the ER, SERCA-dependent $\mathrm{Ca}^{2+}$ uptake is likely a crucial mechanism for refilling. However, as shown in Figure $1 B$, local decreases in $\left[\mathrm{Ca}^{2+}\right]_{\mathrm{ER}}$ induced by PF inputs recovered far faster than recovery in cell-wide ER depletion experiments conducted on neurons ( $\sim 1$ min; Garaschuk et al., 1997; Solovyova et al., 2002; Hartmann et al., 2014). Therefore, it is possible that the rapid refilling of $\mathrm{ER} \mathrm{Ca}^{2+}$ following a PF input occurs through the diffusion of intraluminal $\mathrm{Ca}^{2+}$ from unstimulated segments to depleted segments of the ER, as suggested by studies in other cell types (Mogami et al., 1997; Choi et al., 2006; Petersen and Verkhratsky, 2007).

Using our newly developed ER $\mathrm{Ca}^{2+}$ imaging technology, we were able to directly examine the role of intraluminal $\mathrm{Ca}^{2+}$ diffusion in recovery. We divided dendrites into segments according to their distance from the PF stimulation input site, and compared the PF-induced $\left[\mathrm{Ca}^{2+}\right]_{\mathrm{ER}}$ responses of each segment. The analysis showed that the responses became smaller in magnitude and slower in onset according to the distance of the segment from the input site, which is consistent with a diffusional mechanism (Fig. $2 A, B$ ). The observed $\left[\mathrm{Ca}^{2+}\right]_{\mathrm{ER}}$ dynamics did not appear to be the result of the diffusion of G-CEPIAler itself, because FRAP of G-CEPIA1er within narrow dendritic segments resulted in much slower $t_{1 / 2}$ of fluorescence intensity than that of the $\mathrm{Ca}^{2+}$ signal after PF inputs (Fig. 2C).

Alternatively, the smaller and slower $\left[\mathrm{Ca}^{2+}\right]_{\mathrm{ER}}$ dynamics in the distant dendritic segments can be explained if $\mathrm{IP}_{3}$ generated at the input site reaches the ER in the distant segments by diffusion through the cytosol to induce delayed release of $\mathrm{Ca}^{2+}$. To examine this possibility, we performed simultaneous cytosolic and ER $\mathrm{Ca}^{2+}$ imaging by introducing $\mathrm{X}$-rhod-1, a red color $\mathrm{Ca}^{2+}$ indicator, to the cytosol of G-CEPIA 1 er-expressing PCs, using a patch pipette (Fig. 2D). We observed that immediately beneath the PF stimulation electrode, where $\left[\mathrm{Ca}^{2+}\right]_{\mathrm{ER}}$ decreased rapidly, there was a transient increase in cytosolic $\mathrm{Ca}^{2+}$ (Fig. 2D,E). In the distant segments, however, the delayed decrease in $\left[\mathrm{Ca}^{2+}\right]_{\mathrm{ER}}$ was not accompanied by a detectable increase in cytosolic $\mathrm{Ca}^{2+}$ (Fig.
$2 D, E)$. These results indicate that $\mathrm{Ca}^{2+}$ is not released from the ER in the distant segments, and argue against the alternative possibility that the diffusion of $\mathrm{IP}_{3}$ caused delayed $\left[\mathrm{Ca}^{2+}\right]_{\mathrm{ER}}$ dynamics in the distant dendritic segments.

\section{Diffusion-dependent ER refilling of $\mathrm{Ca}^{2+}$ after PF-induced $\mathrm{Ca}^{2+}$ mobilization}

To estimate the extent to which intraluminal $\mathrm{Ca}^{2+}$ diffusion contributes to the replenishment of $\mathrm{Ca}^{2+}$ within the ER following local decreases in $\left[\mathrm{Ca}^{2+}\right]_{\mathrm{ER}}$, we performed numerical simulations of ER $\mathrm{Ca}^{2+}$ dynamics. Specifically, we modeled and solved a one-dimensional reaction-diffusion equation describing lateral diffusion of $\mathrm{Ca}^{2+}$ within the modeled dendritic structure, as well as $\mathrm{Ca}^{2+}$ pump-dependent $\mathrm{Ca}^{2+}$ uptake and leak from the ER to the cytosol (Fig. 3A). Data fitting using the equation faithfully reproduced the recovery dynamics of G-CEPIA1er fluorescence and indicated the effective diffusion coefficient of $\mathrm{Ca}^{2+}$ within the ER lumen to be $8.4 \mu \mathrm{m}^{2} / \mathrm{s}$ (see Materials and Methods). We confirmed that lateral diffusion is critical by observing a significant slowing of $\left[\mathrm{Ca}^{2+}\right]_{\mathrm{ER}}$ recovery at the central segment when no diffusion was allowed in the simulation (Fig. $3 A$, bottom). In contrast, we showed that $\mathrm{Ca}^{2+}$ uptake provides a relatively minor contribution by a simulation where $\mathrm{Ca}^{2+}$ pump and leak activity was not allowed (Fig. $3 A$, middle).

We next used CPA to experimentally validate the numerical simulations. After the application of CPA to G-CEPIAlerexpressing PCs, we observed a decrease in $\left[\mathrm{Ca}^{2+}\right]_{\mathrm{ER}}$ after a short lag time (Fig. $1 E$ ), indicating that CPA acts by immediately inhibiting SERCA. Treating PCs with CPA for 2 min induced a small but significant decrease in G-CEPIAler fluorescence [mean $( \pm$ SEM $)$ fractional decrease $=0.087 \pm 0.019 ; n=7]$, indicating that SERCA was inhibited by CPA within 2 min of application. We then measured the $t_{1 / 2}$ of PF-induced G-CEPIA1er responses before and $2 \mathrm{~min}$ after CPA treatment. CPA treatment resulted in only a slight increase in $t_{1 / 2}$ (Fig. $3 B$ ). These results are consistent with the prediction of our numerical simulation that there is a 


\section{A}
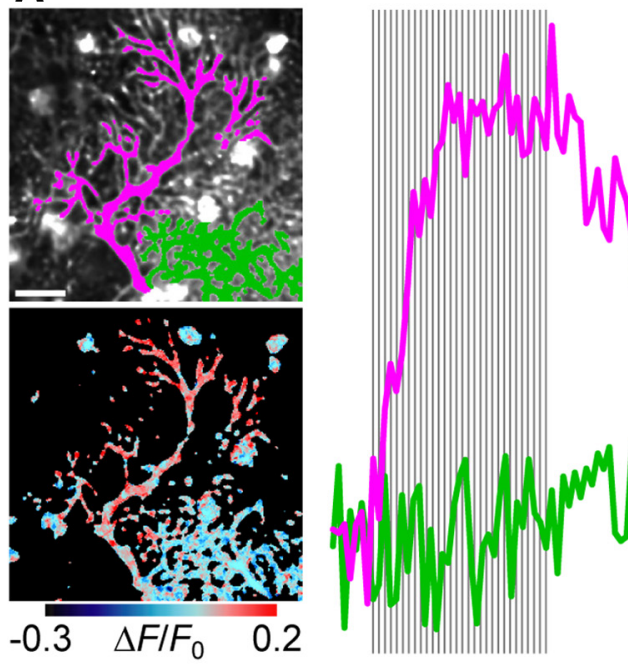

B
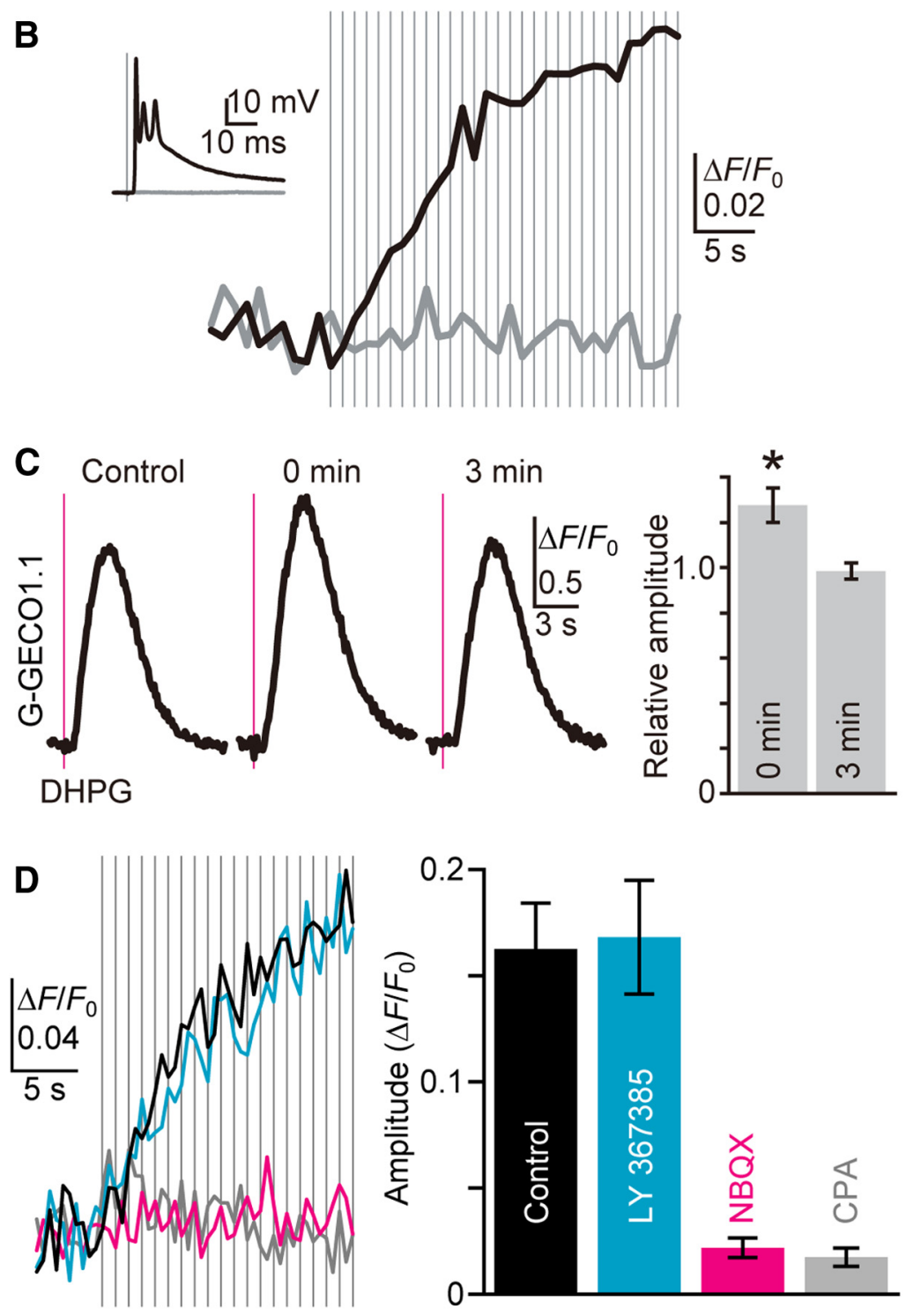

Figure 5. CF activity-induced ER Ca ${ }^{2+}$ overloading. $A$, Representative time courses of mean $\Delta F / F_{0}$ throughout the dendrite of a stimulated PC (magenta in the top image, magenta trace) and a nonstimulated neighboring PC (green in the top image, green trace) upon repetitive CF inputs (30 stimuli at $1 \mathrm{~Hz}$, gray vertical lines) indicate CF-induced ER $\mathrm{Ca}^{2+}$ dynamics in PCs. The pseudo-color image shows the average of 20 consecutive frames during CF stimulation. Scale bar, $20 \mu \mathrm{m}$. B, CF stimulation limited contribution of SERCA to $\mathrm{Ca}^{2+}$ replenishment of the ER following PF stimulation-induced $\mathrm{Ca}^{2+}$ release.

The numerical simulation also predicted that if luminal $\mathrm{Ca}^{2+}$ diffusion is the main source of $\mathrm{Ca}^{2+}$ replenishment, the refilling rate will depend on the spatial distribution of areas of decreased $\left[\mathrm{Ca}^{2+}\right]_{\mathrm{ER}}$, such that the larger the area of $\left[\mathrm{Ca}^{2+}\right]_{\mathrm{ER}}$ decrease, the slower the rate of $\mathrm{Ca}^{2+}$ replenishment. In contrast, if the refilling mechanism is dominated by the activity of SERCA, the recovery rate will not depend on the amplitude and the spatial distribution of the areas of $\left[\mathrm{Ca}^{2+}\right]_{\mathrm{ER}}$ decrease. To distinguish between these possibilities, we analyzed the relationship between the spatial distribution of areas of $\left[\mathrm{Ca}^{2+}\right]_{\mathrm{ER}}$ decrease and the time course of recovery. We found that increasing the stimulation intensity by twofold resulted in increases in both the PF-induced $\mathrm{Ca}^{2+}$ depletion area and $t_{1 / 2}$ (Fig. $3 C-E$ ). We also observed that under conditions of elevated temperature, which enhance the activity of SERCA, there was a delay in the recovery of $\left[\mathrm{Ca}^{2+}\right]_{\mathrm{ER}}$ within the enlarged area of decreased $\left[\mathrm{Ca}^{2+}\right]_{\mathrm{ER}}$ (Fig. $3 E$ ). These results are consistent with the importance of luminal $\mathrm{Ca}^{2+}$ diffusion in $\mathrm{Ca}^{2+}$ replenishment.

\section{Simultaneous replenishment of ER $\mathrm{Ca}^{2+}$ in dendrites and spines}

In neurons, spine necks represent major barriers for cytoplasmic $\mathrm{Ca}^{2+}$ diffusion (Svoboda et al., 1996; Majewska et al., 2000; Sabatini et al., 2002; Hernjak et al., 2005; Noguchi et al., 2005), which raises the possibility that diffusion-dependent refilling of ER is impaired in spines. To address this question, we compared ER

(1 Hz, gray vertical lines) just above the threshold induced EPSP (black inset trace) and G-CEPIA1er response (black trace). In contrast, no EPSP (gray inset trace) and G-CEPIA1er responses (gray trace) were observed in the same $\mathrm{PC}$ upon stimulation just below the threshold. C, Cytoplasmic $\mathrm{Ca}^{2+}$ measurement with G-GEC01.1. $\mathrm{Ca}^{2+}$ mobilization was induced by pressure ejection of DHPG $(1 \mathrm{~mm}, 50 \mathrm{~ms}, 10-30 \mathrm{psi}$, magenta vertical line), either $5-10 \mathrm{~s}(0 \mathrm{~min})$ or $3 \mathrm{~min}$ after $\mathrm{CF}$ stimulation ( 30 pulses at $1 \mathrm{~Hz}$ ). Representative time courses of $\Delta F / F_{0}$ indicate the transient enhancement of mGluR1induced $\mathrm{Ca}^{2+}$ mobilization after $\mathrm{CF}$ stimulation. The summarized bar graph for the amplitude of the responses normalized by the amplitude of the control is shown. $n=7$ (mean \pm SEM). ${ }^{*} p=0.00559, t$ test. $\boldsymbol{D}$, Pharmacological characterization of (F-induced ER $\mathrm{Ca}^{2+}$ dynamics. G-CEPIA1er responses upon CF inputs ( $1 \mathrm{~Hz}$, gray vertical lines) in the control condition (black), or in the presence of LY367385 (100 $\mu \mathrm{M}$, cyan), NBQX (10 $\mu \mathrm{m}$, magenta), or (PA (50 $\mu \mathrm{m}$, gray) are shown. Amplitude is defined as the maximum increase in $\Delta F / F_{0}$ during 20 pulses of (F stimulation. $n=6-13$ (mean \pm SEM). 
$\mathrm{Ca}^{2+}$ dynamics between spines and their parent dendrites. We found that PFinduced G-CEPIAler responses within the spines and their parent dendrites exhibited overlapping time courses (Fig. $4 A$ ). Moreover, following PF inputs, the dynamics of $\left[\mathrm{Ca}^{2+}\right]_{\mathrm{ER}}$ decrease (amplitude and time to peak) did not differ between these two cellular compartments (Fig. 4B), which is consistent with previous observations that, upon PF inputs, there are similarities in $\left[\mathrm{Ca}^{2+}\right]_{\mathrm{cyt}}$ transients in spines and dendrites (Finch and Augustine, 1998; Takechi et al., 1998). Furthermore, we observed no difference in the recovery rate $\left(t_{1 / 2}\right)$ between spines and their parent dendrites (Fig. 4B). It has been shown that SERCA does not accumulate within spines (Takei et al., 1992); thus, the simultaneous recovery we observed supports the notion that spine necks do not represent rate-limiting barriers for diffusion-dependent $\mathrm{Ca}^{2+}$ replenishment in the ER. Earlier studies (Harris and Stevens, 1988; Martone et al., 1993) have suggested that, instead, the critical rate-limiting structure for intraluminal diffusion dynamics is a narrow cross section of the ER tubule found throughout the dendrites and spines.

\section{CF inputs load the ER with $\mathrm{Ca}^{2+}$}

Previous studies have indicated that, in neurons, depolarizationinduced $\mathrm{Ca}^{2+}$ influx can load the ER with $\mathrm{Ca}^{2+}$, thereby potentiating subsequent $\mathrm{Ca}^{2+}$ mobilization (Brorson et al., 1991; Garaschuk et al., 1997; Finch and Augustine, 1998; Fiorillo and Williams, 1998; Stutzmann et al., 2003; Power and Sah, 2005; Hong and Ross, 2007; Hartmann et al., 2014). However, these studies did not directly measure $\left[\mathrm{Ca}^{2+}\right]_{\mathrm{ER}}$. Furthermore, whether physiologically relevant $\mathrm{Ca}^{2+}$ influx can increase $\left[\mathrm{Ca}^{2+}\right]_{\mathrm{ER}}$ is as yet unclear. CFs form strong synapses on PC dendrites in a one-to-one manner and induce large EPSPs followed by dendrite-wide $\mathrm{Ca}^{2+}$ spikes (Kitamura and Häusser, 2011). We found that repetitive CF stimulation using a physiologically relevant frequency $(1 \mathrm{~Hz})$ induced an accumulating increase in $\left[\mathrm{Ca}^{2+}\right]_{\mathrm{ER}}$ throughout the dendrite (Fig. $5 A$, magenta), but not in the adjacent nonstimulated PC (Fig. $5 A$, green). We observed no significant difference in the CF-induced $\left[\mathrm{Ca}^{2+}\right]_{\mathrm{ER}}$ elevation at different dendritic segments despite variations in $\mathrm{CF}$-induced $\left[\mathrm{Ca}^{2+}\right]_{\text {cyt }}$ transients that have been observed along PC dendrites (Otsu et al., 2014). We further confirmed the involvement of CFs by observing that there was a strict correlation between $\left[\mathrm{Ca}^{2+}\right]_{\mathrm{ER}}$ response and CF-EPSPs, in an all-or-none manner (Fig. 5B). CFinduced responses reached a plateau after $10-20$ pulses of stimulation, likely because $\left[\mathrm{Ca}^{2+}\right]_{\mathrm{ER}}$ reached a new equilibrium during the repetitive $\mathrm{Ca}^{2+}$ spikes (Fig. $5 A$ ). Elevated $\left[\mathrm{Ca}^{2+}\right]_{\mathrm{ER}}$ levels returned to the basal level within a few minutes of the cessation of CF inputs, which is consistent with previous observations that the potentiating effect by the preceding depolarization lasted a few minutes (Brorson et al., 1991; Garaschuk et al., 1997; Stutzmann et al., 2003; Hong and Ross, 2007). Using cytoplasmic $\mathrm{Ca}^{2+}$ measurements, we confirmed that CF input trains, comprising 30 pulses at $1 \mathrm{~Hz}$, enhanced subsequent mGluR1mediated $\mathrm{Ca}^{2+}$ mobilization immediately after $\mathrm{CF}$ stimulation, but not 3 min after CF stimulation (Fig. 5C). This result is consistent with earlier studies showing that in PCs, depolarization potentiates the subsequent $\mathrm{Ca}^{2+}$ mobilization (Finch and Augustine, 1998; Hartmann et al., 2014). In this study, we observed both decreasing and increasing changes in the G-CEPIAler fluorescence upon PF and CF inputs, suggesting that the basal $\left[\mathrm{Ca}^{2+}\right]_{\mathrm{ER}}$ is comparable with the dissociation constant of G-CEPIAler (672 $\mu \mathrm{M}$; Suzuki et al., 2014).

Next, we used pharmacological agents to determine which intracellular components are involved in CF-induced ER $\mathrm{Ca}^{2+}$ dynamics. NBQX blocks AMPA receptors, which are the major charge carriers at the CF-PC synapses. Thus, as expected, we found that NBQX blocked the CF-induced G-CEPIAler response (Fig. 5D, magenta). In contrast, LY367385, which is an inhibitor of mGluR1, had no effect (Fig. 5D, cyan). The inhibition of SERCA by CPA abolished the G-CEPIAler response, indicating that $\mathrm{CF}$-induced $\mathrm{Ca}^{2+}$ influx was followed by SERCA-dependent uptake of $\mathrm{Ca}^{2+}$ into the ER (Fig. 5D, gray). In conclusion, we successfully visualized CF-induced ER filling and found evidence strongly suggesting that one function of the ER is as a leaky integrator of CF inputs.

\section{Discussion}

In this study, we successfully used G-CEPIA1er to visualize synaptic activity-evoked $\mathrm{ER} \mathrm{Ca}^{2+}$ dynamics in central neurons, and detected the crucial contribution of intraluminal $\mathrm{Ca}^{2+}$ diffusion to replenishment of $\mathrm{ER} \mathrm{Ca}^{2+}$ after PF-induced local decreases in $\left[\mathrm{Ca}^{2+}\right]_{\mathrm{ER}}$. We also demonstrated the involvement of CF-evoked $\mathrm{Ca}^{2+}$ spikes in the loading of $\mathrm{Ca}^{2+}$ into the ER. These results indicate that the neuronal ER functions as an intracellular $\mathrm{Ca}^{2+}$ tunnel that redistributes stored $\mathrm{Ca}^{2+}$ throughout dendritic arborizations, and as a leaky integrator of synaptic input trains. Thus, the G-CEPIAler-based visualization method that we developed has allowed us to obtain a comprehensive understanding of synaptically evoked $\mathrm{Ca}^{2+}$ flux within the ER lumen and across the ER membrane of PCs (Fig. 6). 


\section{ER functions as a $\mathrm{Ca}^{2+}$ tunnel}

Spatially confined local cytosolic $\mathrm{Ca}^{2+}$ signals have been observed within dendritic arborizations in response to synaptic inputs. Such localized cytosolic $\mathrm{Ca}^{2+}$ transients are realized due to the high $\mathrm{Ca}^{2+}$ buffering power of the cytoplasm, which restricts the diffusion of $\mathrm{Ca}^{2+}$. In contrast, the ER comprises a $\mathrm{Ca}^{2+}{ }_{-}$ containing intracellular network that has been proposed to function as a "Ca ${ }^{2+}$ tunnel" for the transport of intracellular $\mathrm{Ca}^{2+}$. The $\mathrm{Ca}^{2+}$ tunnel hypothesis has been previously tested under reduced experimental conditions, such as acutely isolated pancreatic acinar cells, cardiac myocytes, retinal photoreceptor cells, and dopamine neurons, in which $\left[\mathrm{Ca}^{2+}\right]_{\mathrm{cyt}}$ or $\left[\mathrm{Ca}^{2+}\right]_{\mathrm{ER}}$ is imaged after local application of either $\mathrm{Ca}^{2+}$ or $\mathrm{Ca}^{2+}$-releasing reagents using fine pipettes or caged $\mathrm{Ca}^{2+}$ compounds (Mogami et al., 1997; Park et al., 2000; Choi et al., 2006; Wu and Bers, 2006; Swietach et al., 2008; Picht et al., 2011; Chen et al., 2015). In the current study, we provide strong support for the $\mathrm{Ca}^{2+}$ tunnel hypothesis based on the imaging of PCs under physiologically relevant conditions. Our data indicate that in PCs, the ER functions as a continuous $\mathrm{Ca}^{2+}$ reservoir in which $\mathrm{Ca}^{2+}$ is exchanged between $\mathrm{Ca}^{2+}$-depleted and replete segments in response to repetitive PF inputs (Fig. 6).

Interestingly, we estimated that the effective $\mathrm{Ca}^{2+}$ diffusion coefficient within the ER along the dendrites $\left(8.4 \mu \mathrm{m}^{2} / \mathrm{s}\right)$ was two orders of magnitude lower than the value for free diffusion of $\mathrm{Ca}^{2+}$ in water $\left(\sim 800 \mu \mathrm{m}^{2} / \mathrm{s}\right)$. This disparity is probably due to conditions in the ER such as a high concentration of $\mathrm{Ca}^{2+}$ binding proteins (Pozzan et al., 1994), molecular crowding (Dayel et al., 1999), and the tortuosity of ER tubules (Harris and Stevens, 1988; Martone et al., 1993). It is noteworthy that the ER $\mathrm{Ca}^{2+}$ diffusion coefficient estimated in this study matches well with the value previously measured within the sarcoplasmic reticulum in cardiac myocytes (Swietach et al., 2008), although different values were reported by another group ( $\mathrm{Wu}$ and Bers, 2006; Picht et al., 2011). According to our numerical simulation, despite the low $\mathrm{Ca}^{2+}$ diffusion coefficient within the ER, it still functions as an effective $\mathrm{Ca}^{2+}$ tunnel, due to the low $\mathrm{Ca}^{2+}$ pump and leak activities of the ER membrane. The ER $\mathrm{Ca}^{2+}$ diffusion coefficient that we estimated is comparable to or slightly lower than the value previously measured in the cytoplasmic extract (13 $\mu \mathrm{m}^{2} / \mathrm{s}$; Allbritton et al., 1992). However, PF-induced cytosolic $\mathrm{Ca}^{2+}$ transients are more spatially confined than the corresponding decreases in $\left[\mathrm{Ca}^{2+}\right]_{\mathrm{ER}}$ (Fig. $2 \mathrm{D}$ ). The likely reason for the spatial restriction of the diffusion of cytosolic $\mathrm{Ca}^{2+}$ transients is that cytosolic $\mathrm{Ca}^{2+}$ is efficiently extruded through the plasma membrane. In line with this notion, studies have shown that, in terms of cytoplasmic $\mathrm{Ca}^{2+}$ clearance in central neurons, $\mathrm{Ca}^{2+}$ extrusion across the plasma membrane has a greater contribution than $\mathrm{Ca}^{2+}$ sequestration by SERCA (Fierro et al., 1998; Sabatini et al., 2002; Fig. 6).

\section{ER as a memory of synaptic activity}

The influx of $\mathrm{Ca}^{2+}$ across the plasma membrane is known to transiently potentiate subsequent $\mathrm{Ca}^{2+}$ release from stores within neurons (Brorson et al., 1991; Garaschuk et al., 1997; Stutzmann et al., 2003; Hong and Ross, 2007). Berridge (1998) hypothesized that this phenomenon is mediated by $\mathrm{Ca}^{2+}$ influxdependent elevation of $\left[\mathrm{Ca}^{2+}\right]_{\mathrm{ER}}$, such that the ER functions as an integrator or "memory" of recent neuronal activities accompanying $\mathrm{Ca}^{2+}$ influx. In support of this hypothesis, we showed that $1 \mathrm{~Hz} \mathrm{CF}$ inputs induce an accumulating increase in $\left[\mathrm{Ca}^{2+}\right]_{\mathrm{ER}}$, even though the decay of each CF stimulation-induced $\left[\mathrm{Ca}^{2+}\right]_{\mathrm{cyt}}$ transient had a fast time course relative to the $1 \mathrm{~s}$ inter- val (Kitamura and Häusser, 2011). Furthermore, the elevated $\left[\mathrm{Ca}^{2+}\right]_{\mathrm{ER}}$ lasted a few minutes after the cessation of CF inputs. Therefore, our data support the hypothesis that the ER of PCs can function as a leaky integrator, and the levels of $\left[\mathrm{Ca}^{2+}\right]_{\mathrm{ER}}$ reflect the recent history of CF inputs. Because CFs spontaneously and persistently fire at $\sim 1 \mathrm{~Hz}$ in the cerebellum in vivo, the ER of PCs should be able to integrate $\mathrm{CF}$-evoked $\mathrm{Ca}^{2+}$ spikes to persistently enhance SERCA-dependent filling mechanisms, even under basal conditions. Furthermore, since sensory inputs are known to evoke CF inputs, experience-dependent modulation of $\left[\mathrm{Ca}^{2+}\right]_{\mathrm{ER}}$ may be possible.

\section{References}

Allbritton NL, Meyer T, Stryer L (1992) Range of messenger action of calcium ion and inositol 1,4,5-trisphosphate. Science 258:1812-1815. CrossRef Medline

Berezhkovskii AM, Barzykin AV, Zitserman VY (2009) One-dimensional description of diffusion in a tube of abruptly changing diameter: boundary homogenization based approach. J Chem Phys 131:224110. CrossRef Medline

Berridge MJ (1998) Neuronal calcium signaling. Neuron 21:13-26. CrossRef Medline

Bonora M, Giorgi C, Bononi A, Marchi S, Patergnani S, Rimessi A, Rizzuto R, Pinton P (2013) Subcellular calcium measurements in mammalian cells using jellyfish photoprotein aequorin-based probes. Nat Protoc 8:21052118. CrossRef Medline

Brorson JR, Bleakman D, Gibbons SJ, Miller RJ (1991) The properties of intracellular calcium stores in cultured rat cerebellar neurons. J Neurosci 11:4024-4043. Medline

Chen M, Van Hook MJ, Thoreson WB (2015) $\mathrm{Ca}^{2+}$ diffusion through endoplasmic reticulum supports elevated intraterminal $\mathrm{Ca}^{2+}$ levels needed to sustain synaptic release from rods in darkness. J Neurosci 35: 11364-11373. CrossRef Medline

Choi YM, Kim SH, Chung S, Uhm DY, Park MK (2006) Regional interaction of endoplasmic reticulum $\mathrm{Ca}^{2+}$ signals between soma and dendrites through rapid luminal $\mathrm{Ca}^{2+}$ diffusion. J Neurosci 26:12127-12136. CrossRef Medline

Dayel MJ, Hom EF, Verkman AS (1999) Diffusion of green fluorescent protein in the aqueous-phase lumen of endoplasmic reticulum. Biophys J 76:2843-2851. CrossRef Medline

Edwards FA, Konnerth A, Sakmann B, Takahashi T (1989) A thin slice preparation for patch clamp recordings from neurones of the mammalian central nervous system. Pflugers Arch 414:600-612. CrossRef Medline

Fierro L, DiPolo R, Llano I (1998) Intracellular calcium clearance in Purkinje cell somata from rat cerebellar slices. J Physiol 510:499-512. CrossRef Medline

Finch EA, Augustine GJ (1998) Local calcium signalling by inositol-1,4,5trisphosphate in Purkinje cell dendrites. Nature 396:753-756. CrossRef Medline

Fiorillo CD, Williams JT (1998) Glutamate mediates an inhibitory postsynaptic potential in dopamine neurons. Nature 394:78-82. CrossRef Medline

Fujiwara A, Hirose K, Yamazawa T, lino M (2001) Reduced $\mathrm{IP}_{3}$ sensitivity of $\mathrm{IP}_{3}$ receptor in Purkinje neurons. Neuroreport 12:2647-2651. CrossRef Medline

Garaschuk O, Yaari Y, Konnerth A (1997) Release and sequestration of calcium by ryanodine-sensitive stores in rat hippocampal neurones. J Physiol 502:13-30. CrossRef Medline

Harris KM, Stevens JK (1988) Dendritic spines of rat cerebellar Purkinje cells: serial electron microscopy with reference to their biophysical characteristics. J Neurosci 8:4455-4469. Medline

Hartmann J, Karl RM, Alexander RP, Adelsberger H, Brill MS, Rühlmann C, Ansel A, Sakimura K, Baba Y, Kurosaki T, Misgeld T, Konnerth A (2014) STIM1 controls neuronal $\mathrm{Ca}^{2+}$ signaling, mGluR1-dependent synaptic transmission, and cerebellar motor behavior. Neuron 82:635-644. CrossRef Medline

Hernjak N, Slepchenko BM, Fernald K, Fink CC, Fortin D, Moraru II, Watras J, Loew LM (2005) Modeling and analysis of calcium signaling events leading to long-term depression in cerebellar Purkinje cells. Biophys J 89:3790-3806. CrossRef Medline 
Hong M, Ross WN (2007) Priming of intracellular calcium stores in rat CA1 pyramidal neurons. J Physiol 584:75-87. CrossRef Medline

Ishii K, Hirose K, Iino M (2006) $\mathrm{Ca}^{2+}$ shuttling between endoplasmic reticulum and mitochondria underlying $\mathrm{Ca}^{2+}$ oscillations. EMBO Rep 7: 390-396. CrossRef Medline

Kitamura K, Häusser M (2011) Dendritic calcium signaling triggered by spontaneous and sensory-evoked climbing fiber input to cerebellar Purkinje cells in vivo. J Neurosci 31:10847-10858. CrossRef Medline

Majewska A, Brown E, Ross J, Yuste R (2000) Mechanisms of calcium decay kinetics in hippocampal spines: role of spine calcium pumps and calcium diffusion through the spine neck in biochemical compartmentalization. J Neurosci 20:1722-1734. Medline

Makhnovskii YA, Berezhkovskii AM, Zitserman VY (2010) Diffusion in a tube of alternating diameter. Chem Phys 367:110-114. CrossRef

Martone ME, Zhang Y, Simpliciano VM, Carragher BO, Ellisman MH (1993) Three-dimensional visualization of the smooth endoplasmic reticulum in Purkinje cell dendrites. J Neurosci 13:4636-4646. Medline

Miyawaki A, Llopis J, Heim R, McCaffery JM, Adams JA, Ikura M, Tsien RY (1997) Fluorescent indicators for $\mathrm{Ca}^{2+}$ based on green fluorescent proteins and calmodulin. Nature 388:882-887. CrossRef Medline

Mogami H, Nakano K, Tepikin AV, Petersen OH (1997) $\mathrm{Ca}^{2+}$ flow via tunnels in polarized cells: recharging of apical $\mathrm{Ca}^{2+}$ stores by focal $\mathrm{Ca}^{2+}$ entry through basal membrane patch. Cell 88:49-55. CrossRef Medline

Noguchi J, Matsuzaki M, Ellis-Davies GC, Kasai H (2005) Spine-neck geometry determines NMDA receptor-dependent $\mathrm{Ca}^{2+}$ signaling in dendrites. Neuron 46:609-622. CrossRef Medline

Okubo Y, Kakizawa S, Hirose K, Iino M (2001) Visualization of $\mathrm{IP}_{3}$ dynamics reveals a novel AMPA receptor-triggered $\mathrm{IP}_{3}$ production pathway mediated by voltage-dependent $\mathrm{Ca}^{2+}$ influx in Purkinje cells. Neuron 32: 113-122. CrossRef Medline

Okubo Y, Kakizawa S, Hirose K, Iino M (2004) Cross talk between metabotropic and ionotropic glutamate receptor-mediated signaling in parallel fiber-induced inositol 1,4,5-trisphosphate production in cerebellar Purkinje cells. J Neurosci 24:9513-9520. CrossRef Medline

Otsu Y, Marcaggi P, Feltz A, Isope P, Kollo M, Nusser Z, Mathieu B, Kano M, Tsujita M, Sakimura K, Dieudonné S (2014) Activity-dependent gating of calcium spikes by A-type $\mathrm{K}^{+}$channels controls climbing fiber signaling in Purkinje cell dendrites. Neuron 84:137-151. CrossRef Medline

Palmer AE, Jin C, Reed JC, Tsien RY (2004) Bcl-2-mediated alterations in endoplasmic reticulum $\mathrm{Ca}^{2+}$ analyzed with an improved genetically encoded fluorescent sensor. Proc Natl Acad Sci U S A 101:17404-17409. CrossRef Medline

Park MK, Petersen OH, Tepikin AV (2000) The endoplasmic reticulum as one continuous $\mathrm{Ca}^{2+}$ pool: visualization of rapid $\mathrm{Ca}^{2+}$ movements and equilibration. EMBO J 19:5729-5739. CrossRef Medline

Petersen OH, Verkhratsky A (2007) Endoplasmic reticulum calcium tunnels integrate signalling in polarised cells. Cell Calcium 42:373-378. CrossRef Medline

Picht E, Zima AV, Shannon TR, Duncan AM, Blatter LA, Bers DM (2011) Dynamic calcium movement inside cardiac sarcoplasmic reticulum during release. Circ Res 108:847-856. CrossRef Medline

Power JM, Sah P (2005) Intracellular calcium store filling by an L-type calcium current in the basolateral amygdala at subthreshold membrane potentials. J Physiol 562:439-453. CrossRef Medline

Pozzan T, Rizzuto R, Volpe P, Meldolesi J (1994) Molecular and cellular physiology of intracellular calcium stores. Physiol Rev 74:595-636. Medline

Rodriguez-Garcia A, Rojo-Ruiz J, Navas-Navarro P, Aulestia FJ, GallegoSandin S, Garcia-Sancho J, Alonso MT (2014) GAP, an aequorin-based fluorescent indicator for imaging $\mathrm{Ca}^{2+}$ in organelles. Proc Natl Acad Sci U S A 111:2584-2589. CrossRef Medline

Sabatini BL, Oertner TG, Svoboda K (2002) The life cycle of $\mathrm{Ca}^{2+}$ ions in dendritic spines. Neuron 33:439-452. CrossRef Medline

Sharp AH, McPherson PS, Dawson TM, Aoki C, Campbell KP, Snyder SH (1993) Differential immunohistochemical localization of inositol 1,4,5trisphosphate- and ryanodine-sensitive $\mathrm{Ca}^{2+}$ release channels in rat brain. J Neurosci 13:3051-3063. Medline

Solovyova N, Veselovsky N, Toescu EC, Verkhratsky A (2002) $\mathrm{Ca}^{2+} \mathrm{dy}-$ namics in the lumen of the endoplasmic reticulum in sensory neurons: direct visualization of $\mathrm{Ca}^{2+}$-induced $\mathrm{Ca}^{2+}$ release triggered by physiological $\mathrm{Ca}^{2+}$ entry. EMBO J 21:622-630. CrossRef Medline

Stutzmann GE, LaFerla FM, Parker I (2003) $\mathrm{Ca}^{2+}$ signaling in mouse cortical neurons studied by two-photon imaging and photoreleased inositol triphosphate. J Neurosci 23:758-765. Medline

Suzuki J, Kanemaru K, Ishii K, Ohkura M, Okubo Y, Iino M (2014) Imaging intraorganellar $\mathrm{Ca}^{2+}$ at subcellular resolution using CEPIA. Nat Commun 5:4153. CrossRef Medline

Svoboda K, Tank DW, Denk W (1996) Direct measurement of coupling between dendritic spines and shafts. Science 272:716-719. CrossRef Medline

Swietach P, Spitzer KW, Vaughan-Jones RD (2008) $\mathrm{Ca}^{2+}$-mobility in the sarcoplasmic reticulum of ventricular myocytes is low. Biophys J 95:14121427. CrossRef Medline

Takechi H, Eilers J, Konnerth A (1998) A new class of synaptic response involving calcium release in dendritic spines. Nature 396:757-760. CrossRef Medline

Takei K, Stukenbrok H, Metcalf A, Mignery GA, Südhof TC, Volpe P, De Camilli P (1992) $\mathrm{Ca}^{2+}$ stores in Purkinje neurons: endoplasmic reticulum subcompartments demonstrated by the heterogeneous distribution of the InsP3 receptor, $\mathrm{Ca}^{2+}$-ATPase, and calsequestrin. J Neurosci 12: 489-505. Medline

Tang S, Wong HC, Wang ZM, Huang Y, Zou J, Zhuo Y, Pennati A, Gadda G, Delbono O, Yang JJ (2011) Design and application of a class of sensors to monitor $\mathrm{Ca}^{2+}$ dynamics in high $\mathrm{Ca}^{2+}$ concentration cellular compartments. Proc Natl Acad Sci U S A 108:16265-16270. CrossRef Medline

Verkhratsky A (2005) Physiology and pathophysiology of the calcium store in the endoplasmic reticulum of neurons. Physiol Rev 85:201-279. CrossRef Medline

Wu J, Prole DL, Shen Y, Lin Z, Gnanasekaran A, Liu Y, Chen L, Zhou H, Chen SR, Usachev YM, Taylor CW, Campbell RE (2014) Red fluorescent genetically encoded $\mathrm{Ca}^{2+}$ indicators for use in mitochondria and endoplasmic reticulum. Biochem J 464:13-22. CrossRef Medline

Wu X, Bers DM (2006) Sarcoplasmic reticulum and nuclear envelope are one highly interconnected $\mathrm{Ca}^{2+}$ store throughout cardiac myocyte. Circ Res 99:283-291. CrossRef Medline

Zhao Y, Araki S, Wu J, Teramoto T, Chang YF, Nakano M, Abdelfattah AS, Fujiwara M, Ishihara T, Nagai T, Campbell RE (2011) An expanded palette of genetically encoded $\mathrm{Ca}^{2+}$ indicators. Science 333:1888-1891. CrossRef Medline 